\title{
Clemens W.A. Fritz: From English in Australia to Australi-
} an English. Frankfurt am Main, 2007. Xii+297 pp. ISBN: 9783-631-56702-9. Price: from $€ 53.10$ - $€ 56.80$. Reviewed by Jitka Vlčkovà, University of Brno.

The rise of new fields in linguistics, such as sociolinguistics, psycholinguistics and computational linguistics in the second half of the twentieth century has opened the way to a deeper understanding of language and its functions in social communities. The possibilities presented by a wide spectrum of linguistic reseach triggered interest in language varieties, with English being of prime concern. In his book, From English in Australia to Australian English, Clemens W.A. Fritz demonstrates how language use adapts to current environmental and social conditions, and that the process of language adaptation may sometimes bring along changes in semantics and, consequently, in communicative practices.

C.W.A. Fritz offers the reader a broad view of the circumstances that led imported English to Australia in the $18^{\text {th }}$ century to develop into a distinct variety recognized as Australian English in the $20^{\text {th }}$ century. The book comprises three major parts, entitled The Story of Australian English, A Corpus of OZ Early English (COOEE) and Studies of COOEE. Each part is a complex unit providing background information for the part which is to follow. Fritz gives an intimate account of events, people, relationships and conditions in four distinctive periods of white colonization and settlement. These four periods are later referred to in the discussions on the stages of linguistic developments in Australia. The first period, 1788-1825, which was marked by the struggle for survival in an alien environment, was characterized by the absence of a strong middle class. Convicts were the most numerous group in the colony. The governors were very much concerned with children "who should not follow the wicked ways of their convict parents" (16), and the solution was sought in education. Unlike Europeans, Australians did not hold prejudices and valued a person's achievements more than their origin. This attitude 
gave rise to egalitarianism, which became "Australia's distinguishing characteristic" (23).

Fritz points out the erroneous views of earlier scholars who thought that convicts spoke a uniform and clearly distinct dialect. The fact is that the settlers, both convicts and officers, were a heterogenous society who came from different parts of Britain and Ireland. They widely differed in their dialects and sociolects. Everyday contact between speakers and the consequent dialect mixing resulted in a new koiné - proto-Broad ${ }^{1}$, at that time still very different from any present-day variety. As the largest group of immigrants to Australia came from the south-east of England, their phonology was most influential. Americans, who have always been a small minority in Australia, had very little linguistic influence.

The second period, 1826-1850, witnessed the establishment of new colonies beyond NSW. The population grew not only due to convict transports at the beginning of the period but also thanks to the encouragement of free (assisted) immigration, often from Scotland and Ireland. Scottish and Irish language varieties, however, did not exert much influence. The overall view is that proto-Broad was southern-English in character.

The next period, referred to as the "years of growth" (1851-1875) is marked by the discovery of gold which attracted many immigrants from abroad, and which also caused massive internal migrations. Victoria, Queensland and Tasmania had been officially established by then. Literacy was enhanced by the introduction of compulsory education. The lifting of Stamp Duty and a generally high level of literacy enabled newspapers to be published in Australia.

\footnotetext{
${ }^{1}$ Wikipedia: In linguistics, a koiné language (common language in Greek) is a standard language or dialect, that has arisen as a result of contact between two mutually intelligible varieties (dialects) of the same language. Since the speakers understand one another from before the advent of the koiné, the koineization process is not as rapid as pidginization and creoliza-

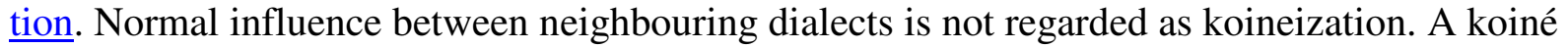
variety emerges as a new spoken variety in addition to the originating dialects; it does not change any existing dialect. This separates koineization from normal evolution of dialects.
} 
Linguistically, the most frequent features of the accents spoken by immigrants combined with the existing proto-Broad gave birth to a new koiné, koiné-General, which later developed into proto-General.

The last period covered in the book is the period of "Nativization and Urbanization" (1876-1900), culminating in the foundation of the Commonwealth of Australia. In the fourth period, the importance and recognition of education was higher than before. Higher education institutions used mostly British teaching materials, British views and standards were promoted, including RP in speech. Industrialization brought along social stratification; the upper classes favoured British standards and RP. Their attitude was fostered by admiration for the new British immigrants establishing themselves successfully in important positions in Australia. The contacts between the two groups resulted linguistically in a new koiné, koiné-Cultivated. It was the young generation then who nativized koiné-Cultivated and consequently made it proto-Cultivated. By 1900 English in Australia was markedly different from other varieties of English but it took Australians several decades to accept it as a distinctive variety of English in its own right.

The second part of the book, which occupies only seventeen pages in the book, is dedicated to the Corpus of OZ Early English. It describes the procedures used to create the corpus. The corpus, which was used in the analyses presented in the next part of the book, contains about two million words. The data came from 100 different sources, such as letters, newspaper reports, legal texts and historical texts published on the internet, to name just a few.

The third part of the book is divided into three major sections. The first one presents the lexis and its enrichment - related to the environment and living conditions the settlers faced: the contact with indigenous peoples and the until then unknown fauna and flora, convicts and bushrangers, the bush, the discovery of gold and life in the city.The last subchapter in this section is concerned with the influence of America, since the contacts were there almost from the very beginning of Australia's establishment as a penal colony (156). In the discussions, the lexical items are introduced by a short note 
on the surroundings, in which they were used whether social or natural. In addition to the data and examples from COOEE, the reader is informed about findings of other scholars.

The second section deals with aspects of morphology. The author starts with features of derivational morphology which are typical of early as well as present-day Australian English. The suffixes $<i e\rangle \mid\langle y\rangle$ (as in Richie) vs. $\langle 0\rangle$ (Richo), <*roo> (as in kangaroo) and <ee $>$ (corroborree or addressee) are introduced as specific features of Australian English word formation. The origin, usage and meaning of these suffixes are explained and the readers are provided with several examples from COOEE. Reduplication and compounding are then dealt with. Both seem to be highly influenced by Aboriginal languages. While reduplication became more frequent thanks to Aboriginal models, early compounds with native and bush labelling indigenous designata receded in favour of Aboriginal terms. Thus early native dog was replaced by dingo.

In the part entitled "Inflectional morphology" Fritz focuses on nonstandard verb inflections (namely present tense $-s$ and was/were levelling) as well as on past tense and past participle formation. He not only highlights specific properties of AusE, but also shows them in context of the contemporary varieties of English world-wide.

The third section deals with word classes and syntax. Pronouns are the first word class treated in this subchapter. The usage of thou, thee, thine, ye, yea, yee, yous and you all is explained and contexts, in which these marginal pronouns occurred, are specified. According to corpus data, IrE is responsible for the expansion of some of these pronouns, especially plural forms of you (yous, yee). Unusual sentence functions of conjunctions (and prepositions) but, and and as are revealed and commented on. While adverbial but could not be found in COOEE at all and subordinating and occurred only to some extent, relative as "was a frequent feature of early English in Australia, enjoying a healthy life in the period covered" (214).

Syntactic aspects (verbal concord with collective nouns, the progressive and the mandative subjunctive) are dealt with in great detail. Firstly, the situation in present-day varieties of English is outlined. 
Secondly, findings from COOEE are summed up and, finally, $19^{\text {th }}$ and $20^{\text {th }}$-century Englishes are compared. Unlike some of the previous subchapters, these thorough and informative analyses are clearly structured and it is not difficult to follow them. The development of AusE as a colonial variety is shown in comparison with the language of the mother country, Great Britain, as well as other colonies. Thus the reader discovers that as far as singular concord is concerned, the colonies were more advanced than Britain. The progressive is still becoming more frequent in present-day English, especially in AusE and NZE. And while should is the most common modal in subjunctive in BrE, there are more possible choices in AusE.

Besides statistical data, Fritz provides his reader with a great deal of sociolinguistic information. When analysing examples from the corpora, he takes into consideration gender, nationality and social status of their authors and types of texts in which they occurred. This enabled conclusions to be made not only on general usage, but also, for example, that men were less likely to use the progressive aspect than women in $19^{\text {th }}$-century AusE.

All parts of the book are amply complemented with examples and tables which provide the reader with more details on the issues discussed, and finally there is an appendix listing the data on texts in COOEE. 